\title{
Simultaneous data-based optimization of a 1D-ecosystem model at three locations in the North Atlantic: Part I-Method and parameter estimates
}

\author{
by Markus Schartau ${ }^{1,2}$ and Andreas Oschlies ${ }^{3}$
}

\begin{abstract}
An optimization experiment is performed with a vertically resolved, nitrogen-based ecosystem model, composed of four state variables (NPZD-model): dissolved inorganic nitrogen $(N)$, phytoplankton $(P)$, herbivorous zooplankton $(Z)$ and detritus $(D)$. Parameter values of the $N P Z D$-model are optimized while assimilating observations at three locations in the North Atlantic simultaneously, namely at the sites of the Bermuda Atlantic Time-Series Study (BATS; 31N 64W), of the North Atlantic Bloom Experiment (NABE; 47N 20W), and of Ocean Weather Ship-India (OWS-INDIA; $59 \mathrm{~N} 19 \mathrm{~W})$. A method is described for a simultaneous optimization which effectively merges different types of observational data at distinct sites in the ocean. A micro-genetic algorithm is applied for the minimization of a weighted least square misfit function. The optimal parameter estimates are shown to represent a compromise among local parameter estimates that would be obtained from single-site optimizations at the individual locations. The optimization yields a high estimate of the initial slope parameter of photosynthesis $(\alpha)$, which is shown to be necessary to match the initial phases of phytoplankton growth. The estimate of $\alpha$ is well constrained by chlorophyll observations at the BATS and OWS-INDIA sites and likely compensates for a deficiency in the parameterization of light-limited growth. The optimization also points toward an enhanced recycling of organic nitrogen which is perceived from a high estimate for the phytoplankton mortality/ excretion rate.
\end{abstract}

\section{Introduction}

One general task of marine ecosystem models is to represent those ecological processes which significantly contribute to biogeochemical fluxes in the ocean. For this purpose, a variety of biological models have been developed (e.g. Evans and Parslow, 1985; Fasham et al., 1990; Steele and Henderson, 1992; Hurtt and Armstrong, 1999; Doney et al., 1996; Moore et al., 2001). These models differ in complexity, from simple models containing three biological state variables up to more complex ones with, presently, some thirty compartments. While more complex models appear to be more realistic at first glance, they

1. Alfred-Wegener-Institut für Polar- und Meeresforschung, Bussestr. 24, 27670 Bremerhaven, Germany.

2. Present address: Marine Sciences Research Center, SUNY, Stony Brook, New York, 11794, U.S.A. email: markus.schartau@stonybrook.edu

3. Institut für Meereskunde, Düsternbrooker Weg 20, 24105 Kiel, Germany. 
usually contain a large number of parameterizations with poorly known parameters that are often difficult to be determined directly from observational or physiological information. As soon as a model becomes too complex, in the sense that it contains unconstrainable parameters (degrees of freedom), it may not be useful for extrapolation to climatic conditions other than those used to tune the model. Hence, the available data places significant limitations on the necessary model complexity (Matear, 1995). When, on the other hand, the model is too simplistic, the simulated biogeochemical fluxes might be seriously wrong due to the absence of important processes. Yet, the minimum complexity that is required for an ecosystem model to reliably reproduce biogeochemical observations while being fully constrainable has not been explored. We believe that an objective data assimilation method will help to resolve this issue. The present study provides tools that may subsequently be applied to a more systematic assessment of different marine ecosystem models, a task far beyond the scope of this work.

The nitrogen-based ecosystem model developed by Fasham et al. (1990) (hereafter named FDM-model) has become a standard model used in various studies ranging from zero-dimensional mixed-layer applications to fully three-dimensional coupled ecosystemcirculation models. Regarding basin-scale coupled physical-biological simulations, as presented by Sarmiento et al. (1993) and Fasham et al. (1993), the FDM-model is one of the more complex models implemented so far. Some of its parameter values were adopted from published laboratory experiments whereas others were approximated from rates derived from in situ measurements. During the subsequent years, the need to seek optimal parameter estimates for the FDM-model from data assimilative investigations was stressed repeatedly (Fasham et al., 1993; Fasham and Evans, 1995).

Local parameter optimizations of the FDM-model were performed at the US-JGOFS station of the Bermuda Atlantic Time-Series Study (BATS) near 31N, 64W and at 47N, 20W (site of the North Atlantic Bloom Experiment, NABE) by Spitz et al. (1998) and Fasham and Evans (1995), respectively. In both studies a zero-dimensional model of the upper ocean's mixed layer was used. Fasham and Evans (1995) could reproduce the observed nitrate and chlorophyll concentrations at the NABE site, as well as the primary production with an optimized set of parameter values. At the BATS site, however, data-assimilation experiments with the FDM-model seemed to be more problematic (Spitz et al., 1998, 2001). These studies also showed that, despite the large number of highquality data available near Bermuda, not all parameters could be constrained by the observations, suggesting that even a 7-component model may have too many degrees of freedom with respect to fitting well-sampled time series data.

Developing an elaborate and simplified FDM-model with a reduced number of parameters, all of which could be well constrained, was the motivation of Hurtt and Armstrong (1996). They proposed a zero-dimensional model which accounts for allometric relationships for the biological rate parameters. A modified version (hereafter named HA-model) was then optimized to data at two locations in the North Atlantic simultaneously (Hurtt and Armstrong, 1999). To simultaneously fit observations at the two sites, namely BATS and 


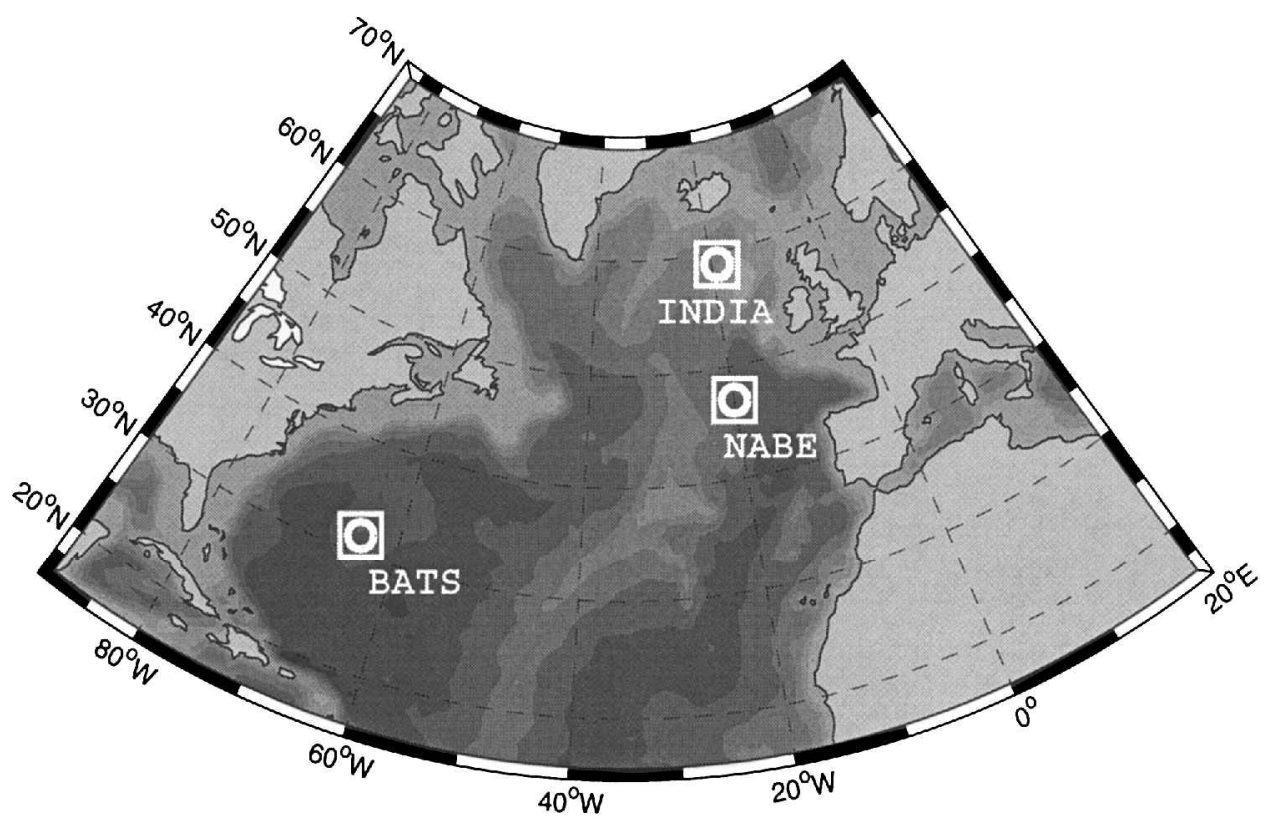

Figure 1. North Atlantic Ocean. The three locations of BATS (31N 64W), of NABE (47N 20W) and of OWS-INDIA $(59 \mathrm{~N} 19 \mathrm{~W})$ used in our data-assimilative investigations are marked. Gray shaded contours show ocean bathymetry.

the location of the Ocean Weather Ship India (OWS-INDIA), the authors had to include a parameterization of iron limitation in their model, which they assumed to be effective at OWS-INDIA but not at the BATS location. To our knowledge, this promising model approach has not yet been applied to a basin-wide 3D-model. A different series of model studies was performed with another reduced FDM-model in a coupled physical-biological model of the North Atlantic (Oschlies and Garçon, 1999; Oschlies et al., 2000). Their ecosystem model combined nitrate and ammonium to dissolved inorganic nitrogen $(N)$. Model compartments such as phytoplankton $(P)$, zooplankton $(Z)$ and detritus $(D)$ remained in the model (hence referred to as $N P Z D$-model) whereas bacteria and dissolved organic nitrogen were not resolved explicitly. For the coupled simulations they relied on parameter values similar to those published by Sarmiento et al. (1993) and Fasham et al. (1993).

The main objective of this study is to identify a single set of parameter values that improves the performance of the NPZD-model at three different locations in the North Atlantic where time-series data are available: at the BATS site $(31 \mathrm{~N}, 64 \mathrm{~W})$, at the NABE site (47N, 20W), and at OWS-INDIA (59N, 19W) (Fig. 1). We attempt to provide optimal parameter estimates for the NPZD-model which can subsequently be used in a basin-scale simulation of the North Atlantic. This is achieved by assimilating observations which were 
collected mainly as part of the Joint Global Ocean Flux Study (JGOFS) at the three sites. In the present paper we investigate optimal parameter estimates and the applicability and robustness of the optimization procedure. Particularly, we will discuss which parameter estimates are likely to compensate for deficiencies of the NPZD-model. A detailed analysis of standing stocks and biological fluxes simulated by the optimized model is the subject of an accompanying paper (Schartau and Oschlies, 2003; this issue).

\section{Method}

\section{a. Model description}

The model's biological state variables $\left(C_{i}\right)$ are strongly simplified representations of either nutrients or organisms that are assumed to be evenly spread within a grid box. The vertical distribution of the state variables is simulated as a function of time, with turbulent vertical mixing coefficients taken from a 3D physical model run (see below). Effects due to vertical advective flow, and horizontal fluxes resulting from a divergent vertical flow field, are not accounted for. The governing one-dimensional equation can be formulated as follows:

$$
\frac{\partial C_{i}}{\partial t}=-w_{i} \frac{\partial C_{i}}{\partial z}+\frac{\partial}{\partial z}\left(K_{\mathrm{\rho}} \frac{\partial C_{i}}{\partial z}\right)+S M S\left(C_{i}\right)
$$

$K_{\rho}$ is the turbulent mixing coefficient and $w_{i}$ is the sinking velocity which becomes nonzero only for detritus. The terms on the right-hand side represent sinking of detritus, turbulent mixing and source minus sink (SMS) terms that describe the inherent biological processes.

The biological interactions among the four compartments of the NPZD-model are sketched in Figure 2. The arrows show the nitrogen fluxes, with symbols indicating those parameters that are associated with the rates for each particular flux. In contrast to previous model versions of this NPZD-model (Oschlies and Garçon, 1999; Oschlies, 2001), not only phytoplankton growth but also all remineralization rates, i.e. the fluxes from $P, Z$, and $D$ to $N$, are temperature dependent. All model parameters are listed in Table 1. The full model equations are listed in the Appendix. The biological model is initialized with vertical nitrate profiles from Conkright et al. (1994). The time-steps of integration are 15 minutes for the biological state variables whereas they are 1 hour for the advective-diffusive equation. The spin-up time equals two identical years with the same physical components as derived for the year 1989 .

\section{b. Physical forcing}

With the aim to achieve a high degree of consistency with a basin-scale ecosystemcirculation model, the one-dimensional ecosystem model is embedded into a physical environment taken from three-dimensional ocean circulation simulations. The chosen 


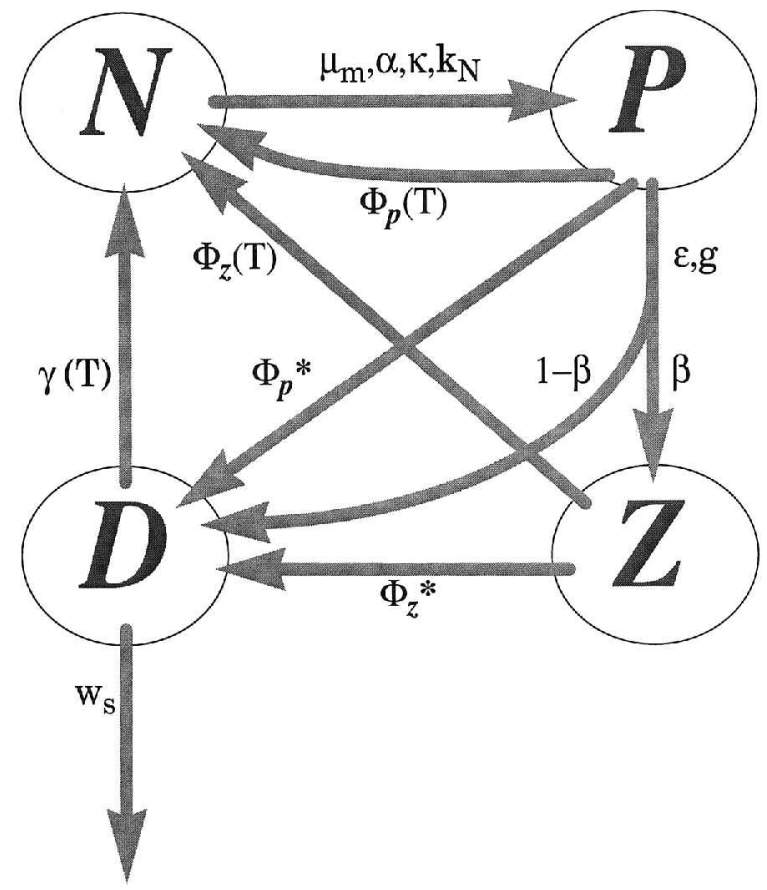

Figure 2. Structure of the ecosystem model. The compartments (state variables) are dissolved inorganic nitrogen $(N)$, phytoplankton biomass $(P)$, herbivorous zooplankton $(Z)$ and detritus $(D)$. The arrows indicate the direction of mass flux. Those parameters which control a particular mass flux are additionally listed. The parameter symbols are explained in Table 1.

ocean circulation model is identical to the one applied by Oschlies and Garçon (1999). The horizontal resolution allows for mesoscale variability ("eddy permitting") with a meridional grid of $1 / 3$ and a zonal grid spacing of $2 / 5$. The water column is partitioned into 37 levels with the first 10 levels resolving the upper 126 meter (see Table 2). Resolving the entire water column down to the bottom excludes the need for an open lower boundary of the model. The fact that vertical grid spacing increases from about $30 \mathrm{~m}$ below the euphotic zone to $250 \mathrm{~m}$ below $1000 \mathrm{~m}$ is considered to have only minor impact on the simulated nitrate supply by deep winter mixing, because nutrient gradients at depth are usually very weak. On the few-year time scales considered here, interactions with the sediment can be neglected.

The 3D-model run from which the physical environment is taken at the three 1D sites was forced with daily mean reanalysis data of the European Center of Medium Range Weather Forecast (ECMWF), covering the period 1989 through 1993 (Nicolas Ferry, personal communication). The one-dimensional ecosystem simulations run here use the same ECMWF surface short-wave radiation data as the basin-scale simulation. 
Table 1. Parameters of the NPZD-model. The first thirteen parameters of the list enter the optimization process.

\begin{tabular}{c|cl|r}
\hline$p_{v}$ & Symbol & \multicolumn{1}{c}{ Parameters for variation } & \multicolumn{1}{c}{ Unit } \\
\hline \hline$p_{1}$ & $\mu_{m}$ & Growth rate parameter & $\mathrm{d}^{-1}$ \\
$p_{2}$ & $\alpha$ & $\begin{array}{l}\text { Slope of photosynthesis versus light } \\
\text { intensity }\end{array}$ & $\mathrm{m}^{2} \mathrm{~W}^{-1} \mathrm{~d}^{-1}$ \\
$p_{3}$ & $\Phi_{m}^{p}$ & Phytoplankton loss rate parameter & $\mathrm{d}^{-1}$ \\
$p_{4}$ & $\Phi_{p}^{*}$ & Phytoplankton quadratic loss & $\mathrm{m}^{3} \mathrm{mmol} \mathrm{N}^{-1} \mathrm{~d}^{-1}$ \\
$p_{5}$ & $k_{N}$ & Half saturation constant of $N$ uptake rate & $\mathrm{mmol} \mathrm{Nm}^{-3}$ \\
$p_{6}$ & $\kappa$ & Attenuation coefficient due to phytoplankton & $\mathrm{m}^{2} \mathrm{mmol} \mathrm{N}^{-1}$ \\
$p_{7}$ & $g$ & Maximum grazing rate & $\mathrm{d}^{-1}$ \\
$p_{8}$ & $\epsilon$ & Prey capture rate & $\mathrm{m}^{6} \mathrm{mmol} \mathrm{N}^{-2} \mathrm{~d}^{-1}$ \\
$p_{9}$ & $\Phi_{m}^{z}$ & Herbivore loss rate parameter & $\mathrm{d}^{-1}$ \\
$p_{10}$ & $\Phi_{z}^{*}$ & Herbivore quadratic mortality & $\mathrm{m}^{3} \mathrm{mmol} \mathrm{N}^{-1} \mathrm{~d}^{-1}$ \\
$p_{11}$ & $\beta$ & Assimilation efficiency of herbivores & $\mathrm{dimensionless}$ \\
$p_{12}$ & $\gamma_{m}$ & Remineralization rate parameter of detritus & $\mathrm{d}^{-1}$ \\
$p_{13}$ & $w_{s}$ & Detrital sinking velocity & $\mathrm{m} \mathrm{d}^{-1}$ \\
\hline & & Fixed parameters & Value and unit \\
\hline \hline & $k_{w}$ & Light attenuation due to water & $0.04 \mathrm{~m}^{-1}$ \\
& $R$ & molar carbon to nitrogen ratio & 6.625 \\
& $f_{\mathrm{PAR}}$ & short-wave fraction of PAR & 0.43 \\
& $C_{\mathrm{ref}}$ & growth coefficient & 1.066 \\
& $c$ & growth coefficient & $1.000\left({ }^{\circ} \mathrm{C}\right)^{-1}$ \\
\hline
\end{tabular}

\section{c. Observations}

At all three locations five types of observations are considered in this study: nitrate + nitrite (DIN), chlorophyll $a(\mathrm{Chl} a),{ }^{14} \mathrm{C}$-primary production (C-PP), particulate organic nitrogen (PON) and zooplankton biomass (ZOO). Whenever nitrite measurements are not available, then only nitrate is considered. All observations are first interpolated onto a 1 meter vertical grid and then averaged over the model's grid boxes. The average of those individual profiles that are available for each month are calculated for each data type within the upper fifteen model layers, covering a depth range of 411 meters which is usually well resolved by the measurements. Note that these monthly-mean values have to be derived from a relatively sparse sampling schedule (particularly at the NABE and OWS-INDIA sites with sometimes none or only a single profile per month). Hence, these monthly values do not necessarily represent true monthly means. Table 3 gives an overview of the observations considered.

Location $31 N$ 64W. Near Bermuda, data are available from the BATS, as a part of the U.S. JGOFS project (Michaels and Knap, 1996). The BATS data are provided by the Bermuda Biological Station for Research (BBSR). [BATS extraction site http://www.bbsr.edu/users/ ctd/] Except for zooplankton biomass, all monthly mean values are obtained from 
Table 2. Vertical levels of the numerical model grid. Units are meters.

Vertical layers of the NPZD-model

\begin{tabular}{cr} 
Model level & Depth of grid po \\
1 & 5.50 \\
2 & 17.00 \\
3 & 29.00 \\
4 & 41.00 \\
5 & 53.00 \\
6 & 65.50 \\
7 & 78.50 \\
8 & 91.50 \\
9 & 104.50 \\
10 & 118.50 \\
11 & 140.50 \\
12 & 179.55 \\
13 & 232.60 \\
14 & 295.03 \\
15 & 370.21 \\
16 & 462.51 \\
17 & 577.37 \\
18 & 721.47 \\
19 & 900.89 \\
20 & 1125.04 \\
21 & 1375.04 \\
22 & 1625.04 \\
23 & 1875.04 \\
24 & 2125.04 \\
25 & 2375.04 \\
26 & 2625.04 \\
27 & 2875.04 \\
28 & 3125.04 \\
29 & 3375.04 \\
30 & 3625.04 \\
31 & 3875.04 \\
32 & 4125.04 \\
33 & 4375.04 \\
34 & 4625.04 \\
35 & 4875.04 \\
36 & 5125.04 \\
37 & 5375.04 \\
\hline & \\
\hline &
\end{tabular}

Depth of grid box bottom

Thickness of grid box

$\begin{array}{rr}11.00 & 11.00 \\ 23.00 & 12.00 \\ 35.00 & 12.00 \\ 47.00 & 12.00 \\ 59.00 & 12.00 \\ 72.00 & 13.00 \\ 85.00 & 13.00 \\ 98.00 & 13.00 \\ 111.00 & 13.00 \\ 126.00 & 15.00 \\ 155.00 & 29.00 \\ 204.09 & 49.09 \\ 261.10 & 57.01 \\ 328.95 & 67.85 \\ 411.47 & 82.52 \\ 513.54 & 102.07 \\ 641.19 & 127.65 \\ 801.74 & 160.55 \\ 1000.04 & 198.30 \\ 1250.04 & 250.00 \\ 1500.04 & 250.00 \\ 1750.04 & 250.00 \\ 2000.04 & 250.00 \\ 2250.04 & 250.00 \\ 2500.04 & 250.00 \\ 2750.04 & 250.00 \\ 3000.04 & 250.00 \\ 3250.04 & 250.00 \\ 3500.04 & 250.00 \\ 3750.04 & 250.00 \\ 4000.04 & 250.00 \\ 4250.04 & 250.00 \\ 4500.04 & 250.00 \\ 4750.04 & 250.00 \\ 5000.04 & 250.00 \\ 5250.04 & 250.00 \\ 5500.04 & \\ & 250.00\end{array}$


Table 3. Collected data for the data-assimilation experiment at three locations in the North Atlantic. Data types: dissolved inorganic nitrogen (DIN); Chlorophyll $a$ (Chl); Carbon-based Primary Production (CPP); Particulate Organic Nitrogen (PON); Zooplankton biomass given in nitrogen units (ZOO). Data sources: ${ }^{1}$ US-JGOFS, BBSR; ${ }^{2}$ Caron et al. (1995); ${ }^{3}$ Koeve, personal communication; ${ }^{4}$ Roy Lowry (BODC), personal communication; ${ }^{5}$ Fasham and Evans (2000), Verity et al. (1993), and Fasham, personal communication; ${ }^{6}$ Williams (1988), and data from 1996-1997 collected as part of PRIME. The number of profiles used for the construction of monthly representatives, and the seasonal coverage of the final climatology.

\begin{tabular}{|c|c|c|c|c|}
\hline Area of observation & Data type & $\begin{array}{l}\text { Number of } \\
\text { profiles }\end{array}$ & Years & Seasonal representation/month \\
\hline \multirow{5}{*}{$\begin{array}{l}\text { 31N 20W } \\
\quad \text { (BATS site) }\end{array}$} & $\operatorname{DIN}^{1}$ & 77 & 1989-1993 & 12 months \\
\hline & $\mathrm{Chl}^{1}$ & 75 & 1989-1993 & 12 months \\
\hline & $\mathrm{CPP}^{1}$ & 67 & 1989-1993 & 12 months \\
\hline & $\mathrm{PON}^{1}$ & 77 & 1989-1993 & 12 months \\
\hline & $\mathrm{ZOO}^{2}$ & 6 & 1989,1990 & 3 months; $3 / 4 / 8$ \\
\hline \multirow{5}{*}{$\begin{array}{l}\text { 47N 20W } \\
\quad \text { (NABE site) }\end{array}$} & $\mathrm{DIN}^{3}$ & 96 & 1989-1997 & 9 months; $1 / 2 / 3 / 4 / 5 / 7 / 8 / 9 / 10$ \\
\hline & $\mathrm{Chl}^{3}$ & 100 & 1989-1997 & 9 months; $1 / 2 / 3 / 4 / 5 / 7 / 8 / 9 / 10$ \\
\hline & $\mathrm{CPP}^{4}$ & 29 & 1989 & 4 months; $4 / 5 / 7 / 8$ \\
\hline & $\mathrm{PON}^{4}$ & 48 & 1989-1993 & 3 months; $4 / 5 / 7$ \\
\hline & $\mathrm{ZOO}^{5}$ & 12 & 1989 & 3 months; $5 / 6 / 7$ \\
\hline \multirow[t]{5}{*}{$\begin{array}{l}\text { 59N 19W } \\
\quad \text { (OWS-INDIA site) }\end{array}$} & $\mathrm{DIN}^{6}$ & 97 & $\begin{array}{c}1971-1975 \\
1996\end{array}$ & 8 months; $3 / 4 / 5 / 6 / 7 / 8 / 9 / 10$ \\
\hline & $\mathrm{Chl}^{6}$ & 335 & $\begin{array}{l}1971-1975, \\
1996-1997\end{array}$ & 8 months; $3 / 4 / 5 / 6 / 7 / 8 / 9 / 10$ \\
\hline & $\mathrm{CPP}^{6}$ & 78 & $\begin{array}{l}1970-1975 \\
1997\end{array}$ & 8 months; $3 / 4 / 5 / 6 / 7 / 8 / 9 / 10$ \\
\hline & $\mathrm{PON}^{6}$ & 14 & 1996 & 2 months; $6 / 7$ \\
\hline & $\mathrm{ZOO}^{6}$ & 20 & 1996 & 2 months; $6 / 7$ \\
\hline
\end{tabular}

bi-weekly to monthly data, covering the years 1989-1993. Zooplankton biomass is taken from measurements of heterotrophic nano- and microzooplankton (Caron et al., 1995).

$47 \mathrm{~N} 20 \mathrm{~W}$. Here, most measurements were taken during NABE (Ducklow and Harris, 1993) in the year 1989. Therefore, the monthly observational representatives are biased toward 1989. The initial data base was received from the British Oceanographic Data Center (BODC) and extended by German JGOFS investigations until 1996 (Koeve, personal communication), also available through the German JGOFS data management. All data entering the calculations are selected from a $5 \times 5$ degree area $(17.5 \mathrm{~W}-22.5 \mathrm{~W}, 44.5 \mathrm{~N}-$ 49.5N). Microzooplankton biomass data are taken from Fasham and Evans (2000) who referred to measurements of Verity et al. (1993) and two additional observations made in late summer of 1989. 
$59 \mathrm{~N} 19 \mathrm{~W}$. Most observations yielding a good seasonal coverage at this northern Atlantic site were taken during the years 1971-1974 (Williams, 1988). Although some additional data were collected in 1989, 1996, and 1997 as part of the Plankton Reactivity In the Marine Environment (PRIME) project; the derived monthly means are dominated by data from the early 1970s. As for the NABE site, only data within a $5 \times 5$ degree area are considered $(16.5 \mathrm{~W}-21.5 \mathrm{~W}, 56.5 \mathrm{~N}-61.5 \mathrm{~N})$.

\section{d. Cost function}

$i$. Definition. The cost function is defined as a sum of weighted least square misfits between model results and observations. In order to compute these misfits one could sample the model at the same times and locations as the observations were taken. However, with the physics taken from an eddy-permitting model forced by daily atmospheric winds and heat fluxes, large model-data misfits can arise already from small phase errors in the model. For example, misplaced eddies or systematic errors in the buoyancy budget may easily change the onset of the spring bloom by several days to weeks. Temporal weighting terms could be introduced but are hardly justifiable when assimilating observations at OWS-INDIA, which were predominantly taken in periods (1971-74) not covered by the model forcing (1989-93). To reduce the likely mapping of physical phase errors into the cost function and hence into the optimization of biological model parameters, it was decided to use only monthly-averaged data and monthly-averaged model results instead. Because the available observations do not resolve interannual variability of the simulation period at OWS-INDIA and only marginally at the NABE site, it was further decided to map all available observations of all years into a single "climatological" composit for each month. Initial tests using a cost function composed of misfits of such monthly "climatological" observations and "climatological" monthly model means were not successful because the cost function turned out to be insensitive to unrealistic model drifts over the five-year simulation period. In order to get a better handle on such model drifts, we proceeded by comparing the simulated monthly means of each individual year of the five-year simulation with the monthly "climatological" observations. Still, results were not fully satisfactory, and eventually we resorted to include an additional steady-state constraint to the cost function (see below).

At the end of this iterative process, the total cost function used for the simultaneous optimization at the three sites is defined as follows: the total cost combines the individual cost function contributions, $\mathscr{T}_{l}$, from the three locations:

$$
\mathscr{T}_{\text {total }}=\frac{1}{2} \sum_{l=1}^{3} \mathscr{T}_{l}
$$

with $l$ being the location index. The individual cost functions are split up into two parts:

$$
\mathscr{T}_{l}=\sum_{y=1}^{5} \frac{\mathscr{T}_{y l}}{\Psi_{l}}+\frac{1}{s^{2}}\left(N_{89}^{\text {total }}-N_{y}^{\text {total }}\right)_{l}^{2}
$$


with

$$
N_{y}^{\text {total }}=\int_{\text {year }=y} \int_{z=1 \mathrm{~m}}^{411 \mathrm{~m}}(N+P+Z+D) d z d t .
$$

The first term describes the data-model misfits and includes a scaling factor $\Psi_{l}$ for the individual stations discussed below. The second term is the steady-state constraint which penalizes large deviations from the total nitrogen inventory reached after spin up. The integral $N_{y}^{\text {total }}$ stands for the total nitrogen mass within the upper 411 meters of the year $y$. This integral is calculated for each year and compared with the initial nitrogen inventory (after the model's two-year spin up) of the year $1989\left(N_{89}^{\text {total }}\right)$. This second term is based on a plausible, albeit subjective argument, in order to avoid large systematic drifts that can occur in the simulated nitrogen inventory at the individual stations. It actually states that biological production, based on newly entrained nutrients (new production), should not deviate too much from the biogenic export flux. Note, however, that this term will also penalize interannual variability in the model as far as the total nitrogen inventory is affected. The corresponding standard deviation $s$ is chosen to be $5 \%$ of the initial inventory of 1989. At every location the annual data-model misfit contributions to the cost function are calculated as follows:

$$
\mathscr{T}_{y l}=\sum_{j}^{J} \frac{1}{\mathcal{N}_{j l}} \sum_{m}^{\mathcal{N}_{j l}} \sum_{k}^{K} \frac{1}{\sigma_{j}^{2}}\left(f_{j}-y_{j}^{o b s}\right)_{m k}^{2}
$$

with the monthly "climatological" representative $y_{j m}^{o b s}$ of type $j$ and the modeled monthly mean $\left(f_{j m}\right)$ of year $y$. The total number of observational types is $J=5$ (DIN, Chl $a$, C-PP, PON, and ZOO). $\mathcal{N}_{j l}$ is the number of months for which observations of type $j$ at location $l$ are available. The maximal depth for data to be assimilated into the model is 411 meters which is equivalent to the bottom of the $K=15$ grid box. Correlations among the different variables are not accounted for. Division by the number of available observational months gives same weights to observations obtained only during a few months (e.g. zooplankton) compared to those covering a more complete seasonal cycle, see Table 3 . The assigned weights for DIN are $\sigma_{D I N}=0.1 \mathrm{mmol} \mathrm{N} \mathrm{m}^{-3}$. For Chl $a$ and PON concentrations weights of $\sigma_{C h l}=0.01 \mathrm{mg} \mathrm{m}^{-3}$ and $\sigma_{P O N}=0.0357 \mathrm{mmol} \mathrm{m}^{-3}\left(\approx 0.5 \mathrm{mg} \mathrm{m}^{-3}\right)$ are assumed, respectively. Because of large differences in primary production among the three sites, different weights of $15 \%$ of the annual mean primary production at the respective site are considered, yielding $\sigma_{P P}=0.8 \mathrm{mg} \mathrm{C} \mathrm{m}^{-3} \mathrm{~d}^{-1}$ for the OWS-INDIA site, $1.0 \mathrm{mg} \mathrm{C} \mathrm{m}^{-3} \mathrm{~d}^{-1}$ for the NABE site and $0.3 \mathrm{mg} \mathrm{C} \mathrm{m}^{-3} \mathrm{~d}^{-1}$ for the BATS site. The weights for zooplankton biomass are set to $\sigma_{Z O O}=0.01 \mathrm{mmol} \mathrm{N} \mathrm{m}^{-3}$ at all locations.

ii. Scaling of stations. The simplest idea for an overall cost function is to add together all weighted least square misfits of the three locations. Unfortunately, this results in a strong bias of the solution toward one particular location. For instance, as soon as some sort of observation (e.g. chlorophyll concentrations) differs between two locations by one order of 
magnitude, the same relative model-data misfits produce different absolute contributions to the cost function. In test experiments without any scaling of the locations, the optimization converged toward parameter values that generated a model solution with extinct biology at the location with lowest productivity and biomass (in our case at the BATS site). To ensure that similar relative misfits at the different locations give similar cost function contributions, a scaling factor $\Psi_{l}$ is introduced that considers averaged observational values at the respective location $l$ :

$$
\Psi_{l}=\frac{1}{2} \sum_{j=1}^{J} \frac{\left(y^{\overline{o b s}}\right)_{j}^{2}}{\sigma_{j}^{2}}
$$

with the subscript $j$ referring to the data type. At each location the square of the averaged observation (in space and time) is divided by the assumed weights, as prescribed above.

\section{e. Optimization procedure}

i. Micro-genetic algorithm ( $\mu G A)$ for optimization. Schartau et al. (2001) showed that under realistic conditions, especially if model deficiencies exist, a gradient technique can produce optimal solutions which are sensitive to the initial parameter guesses. For robust parameter estimates they had to perform hundreds of individual optimizations, starting from a variety of initial parameter guesses. Intercomparisons of various methods for the optimization of parameter values of marine biogeochemical models (Vallino, 2000; Athias et al., 2000) revealed some advantages of sophisticated stochastic algorithms such as genetic algorithms. Stochastic or quasi-stochastic algorithms do not require special programming efforts for the calculation of the cost function's gradient (e.g., coding of an adjoint model). Furthermore, they are more robust than pure gradient-descent techniques in cases when the cost function contains regions with plane-geometry that result from low sensitivities to parameter variations. For this reason, we resort to the concept of genetic algorithms (GA) (Holland, 1975; Goldberg, 1989).

When applying a GA for parameter optimization, a single set of parameters (parameter vector) is represented by an individual which is coded as a binary string (similar to genes of a chromosome). A generation is set up by a prescribed number $(n)$ of individuals. Selection of individuals, recombination of genes (crossover), and mutation of individuals are the basic operations regarded in genetic algorithms. The selection process follows the evolutionary principle of "survival of the fittest," with the fitness being expressed by a small cost function value. The recombination operation describes the exchange of genes among the selected individuals (parents), setting up an offspring generation with new parameter vectors (children). Often mutation is also regarded. Mutation induces small modifications to some children and therefore brings in new information that is independent of the selected parents.

In this study, we apply a micro-genetic algorithm ( $\mu \mathrm{GA})$, coded and published by Carroll (1996). Numerical details of the $\mu \mathrm{GA}$ are described by Krishnakumar (1989) who 
Table 4. Parameter setup for optimization. One set of parameter values (parameter vector) is represents by an individual with a binary string. The increments yield the highest precision that, for each parameter, can be achieved with the $\mu \mathrm{GA}$. The length of a single bit string of one parameter (or number of binary digits) describes the number of possible values between lower and upper bound.

Parameter configuration for micro-genetic algorithm

$\begin{array}{lcccc}\text { Parameter } & \text { Lower bound } & \text { Upper bound } & \text { Increment } & \text { \# of possibilities } \\ \mu_{m} & 0.200 & 1.470 & 0.010 & 128 \\ \alpha & 0.001 & 0.256 & 0.001 & 256 \\ \Phi_{m}^{p} & 0.000 & 0.635 & 0.005 & 128 \\ \Phi_{p}^{*} & 0.010 & 0.955 & 0.015 & 64 \\ k_{N} & 0.100 & 0.730 & 0.010 & 64 \\ \kappa & 0.010 & 0.073 & 0.001 & 64 \\ g & 0.025 & 1.600 & 0.025 & 64 \\ e & 0.025 & 1.600 & 0.025 & 64 \\ \Phi_{m}^{z} & 0.000 & 0.635 & 0.005 & 128 \\ \Phi_{z}^{*} & 0.010 & 0.955 & 0.015 & 64 \\ \beta & 0.300 & 0.935 & 0.005 & 64 \\ \gamma_{m} & 0.020 & 0.146 & 0.002 & 128 \\ w_{s} & 1.000 & 128.0 & 1.000 & \end{array}$

first presented the algorithm as being able to optimize nonstationary functions. The $\mu \mathrm{GA}$ is based on the same operations as the general GA, but it does not contain mutation and gives greater emphasis on elitism principles. An elitism operator assures that information of the very best individual (parameter set) is retained for recombination. As soon as all individuals of one generation show less than 5\% difference among each other, then a new random population is generated, apart from the best individual which is saved. This process is repeated several times. Hence, while general convergence is achieved, the full parameter space is explored further. This convergence characteristic is well suited for our optimization problem.

The population size is set equal to the numbers of parameters of interest, $n=13$. This is not mandatory, but was found to be a good choice in test experiments (Schartau, 2001). A redundant control parameter is added to the optimization process. Such a control parameter has no effect on the cost function and thereby allows testing for erroneous convergence. The total number of generations is set to 2000 , for which all experiments showed a well-converged cost function value. For recombination a single-pointed crossover (exchange of bit-strings) is applied with a crossover probability of 1.0. Table 4 lists the different components of the parameter vector to be optimized, their respective upper and lower bonds and the resolution used by the optimization algorithm to generate random samples in parameter space.

ii. Errors of parameter estimates. In order to assess the reliability of the optimization algorithm and to obtain an estimate of the errors of the respective optimal parameters 


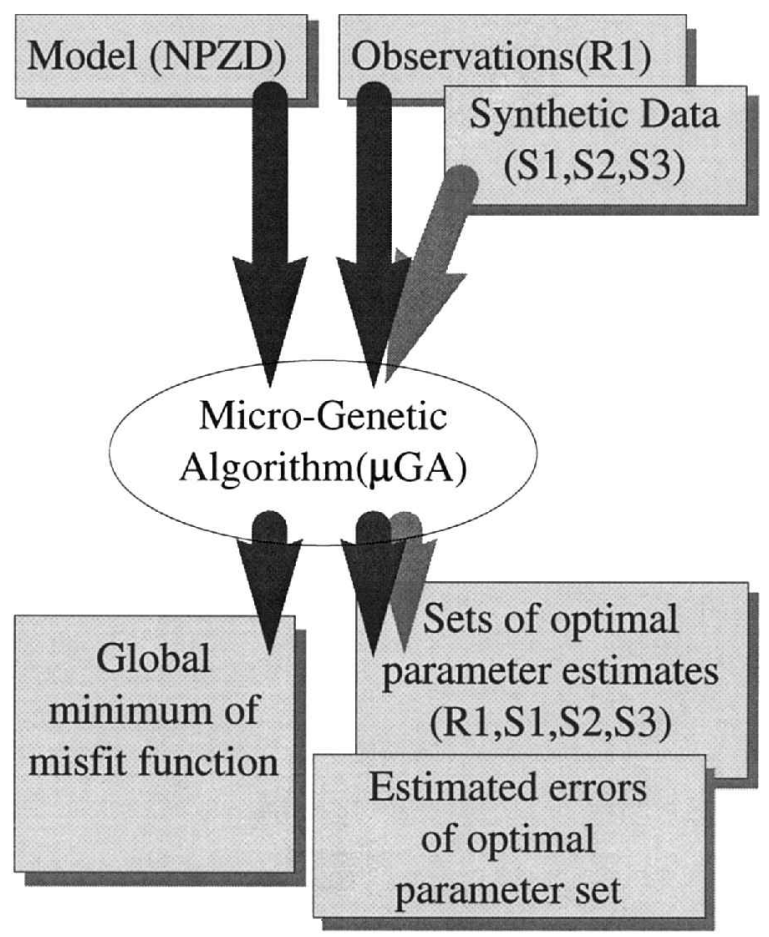

Figure 3. Sketch of the optimization procedure.

generated by this method, a total of four optimizations are performed (Fig. 3). The basic concept is to run additional optimizations with the original data being replaced by a synthetic data set, $y^{\text {syn }}$, generated by adding Gaussian noise $\eta$ to the observations, with a noise variance equivalent to the error variances $\sigma_{j}^{2}$ as used in the cost function Eq. 5:

$$
y_{j k m}^{s y n} \equiv y_{j k m}^{o b s}+\eta\left(\sigma_{j}^{o b s}\right),
$$

with $j, k, m$ referring to data type, depth level, and month, respectively. This approach is related to the Monte Carlo bootstrap method (Efron, 1994). Computational costs restrict us to only three synthetic data sets that are utilized for additional optimizations, of which each single optimization requires 26000 model runs per location. On a $677 \mathrm{MHz}$ DEC/ALPHA work station this results in a total of 308 hours CPU time for the entire procedure.

The optimization with the original data set $y_{o k m}^{o b s}$ produces a best estimate, $\hat{\mathbf{p}}_{0}$, of the parameter vector. Together with the three parameter vectors $\hat{\mathbf{p}}_{i}^{\text {syn }}$ that result from the optimizations with the three synthetic data sets $y_{j k n}^{s y n}$, four independent optimization results (realizations) are then available. An estimate for the expected error in the optimal parameter set $\hat{\mathbf{p}}_{0}$ can then be constructed from two terms: A first error estimate, $\left(\widehat{\sigma_{s d}}\right)_{v}$, is given by the standard deviation with respect to the mean value obtained from all four 
realizations. A second term, $(\hat{\epsilon})_{v}$ accounts for the deviation of the best parameter estimate $\hat{\mathbf{p}}_{0}$ from the mean value $\langle\hat{p}\rangle$ :

$$
(\hat{\epsilon})_{v}=\left(\hat{p}_{0}-\langle\hat{p}\rangle\right)_{v} .
$$

Assuming these two error contributions to be independent, the approximate error variance of the optimal parameter set becomes

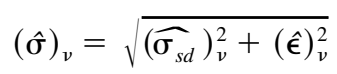

where $v$ refers to the respective component of the parameter vector. Note that this error estimate includes parameter uncertainties that arise from errors in the individual observations, from possible redundancies in the model structure that give rise to parameter combinations that cannot be constrained by any data, and from potential deficiencies of the optimization routine that may induce some scatter in the final solutions.

\section{Results}

\section{a. Minimization of the cost function}

All four optimizations performed (real observations plus three sets of observations with added noise) result in a significant decrease of the cost function values (hereafter called 'costs') with respect to the initial values. The initial costs of the first generation range between $\mathscr{T}_{\text {total }}=157$ and 1503, whereas the minimum yields a cost of $\mathscr{T}_{\text {total }}=61$ (a $61 \%$ decrease for the lower end of the range of initial values). Since no information on the probability density function exists with regard to our optimization problem, it is impossible to describe an expectation value for the cost function of an optimized model that is consistent with the observations. Nevertheless, a reference cost function value can be derived by generating pseudo observations from the optimized model. These model data are sampled and processed in the same way as the real observations. By construction, these pseudo data are fully consistent with the model. When computing the cost function for these pseudo data in the same way as described for the real data in the method section, the resulting reference cost accounts for all preprocessing errors, e.g. those resulting from biases in the monthly data averages due to sparse sampling. Even a perfect model could not produce a cost function value lower than that given by this reference value. In Table 5 the cost function contributions at all three locations are shown for the optimal configurations together with the reference values. In addition, costs of a traditional parameter configuration are presented which rely on parameter values similar to those applied in Oschlies and Garçon (1999) and Oschlies et al. (2000). The traditional values for the linear and quadratic phytoplankton losses $\left(\Phi_{p}\right.$ and $\left.\Phi_{p}^{*}\right)$ are taken from Oschlies (2001). No traditional parameter values exist for the temperature-dependent remineralization rates. We, therefore, relate the previously published rates to the parameterization with temperature by dividing the original rates by a factor of 3.5 , which is the average value of the Eppley (1972) function over a temperature range from 5 through $28^{\circ} \mathrm{C}$. The applied 
Table 5. Comparison of cost function contributions. The optimal configuration resolves the contributions of the best solution found after optimization. The reference values are derived from the optimal run with model results being extracted and processed similar to observational data at the dates of measurements. The traditional cost function relies on a model run with a formerly applied parameter set.

Cost function contributions

$\begin{array}{llrrr}\text { Configuration } & J_{\text {total }} & J_{B A T S} & J_{N A B E} & J_{O W \text { W-INDIA }} \\ \text { Optimal } & 60.59 & 17.71 & 25.04 & 17.84 \\ \text { Reference } & 21.65 & 4.72 & 14.17 & 2.75 \\ \text { Traditional } & 80.86 & 29.91 & 26.43 & 24.52\end{array}$

traditional parameter set is listed in Table 6. The success of the optimization becomes evident when comparing the individual misfit contributions of the optimal fit and the traditional configuration. For the total costs, the misfits have been reduced by $25 \%$. As desired, the simultaneous optimization has not only reduced the overall model data misfit but also the cost function contributions at each individual station. However, the minimum cost function still departs from the reference solution by a factor of 2.8. Such a failure might not seem very surprising, since the reference value could only be achieved under ideal conditions with a perfect model.

\section{b. Optimal parameter values}

A general feature of stochastic minimization algorithms is the very large number of cost function evaluations. Mapping all the cost function values generated during the minimiza-

Table 6. The model's parameter values. Traditional values refer to those typically applied in ecosystem models (see text). The best combination of parameter values $\widehat{\mathbf{p}_{0}}$ is given together with approximated errors $\hat{\boldsymbol{\sigma}}$.

\section{Parameters for optimization}

$\begin{array}{rcccc}v & \text { Symbol } p_{v} & \text { Unit } & \text { Traditional } & \text { Optimal estimates: } \hat{p_{0}} \pm \hat{\sigma} \\ 1 & \mu_{m} & \mathrm{~d}^{-1} & 0.600 & 0.270 \pm 0.033 \\ 2 & \alpha & \mathrm{m}^{2} \mathrm{~W}^{-1} \mathrm{~d}^{-1} & 0.025 & 0.256 \pm 0.036 \\ 3 & \Phi_{m}^{p} & \mathrm{~d}^{-1} & 0.014 & 0.040 \pm 0.013 \\ 4 & \Phi_{p}^{*} & \mathrm{~m}^{3} \mathrm{mmol} \mathrm{N}^{-1} \mathrm{~d}^{-1} & 0.050 & 0.025 \pm 0.014 \\ 5 & k_{N} & \mathrm{mmol} \mathrm{Nm}^{-3} & 0.500 & 0.700 \pm 0.010 \\ 6 & \kappa & \mathrm{m}^{2} \mathrm{mmol} \mathrm{N}^{-1} & 0.030 & 0.047 \pm 0.010 \\ 7 & g & \mathrm{~d}^{-1} & 2.000 & 1.575 \pm 0.102 \\ 8 & \epsilon & \mathrm{m}^{6} \mathrm{mmol} \mathrm{N}^{-2} \mathrm{~d}^{-1} & 1.000 & 1.600 \pm 0.028 \\ 9 & \Phi_{m}^{z} & \mathrm{~d}^{-1} & 0.009 & 0.010 \pm 0.003 \\ 10 & \Phi_{z}^{*} & \mathrm{~m}^{3} \mathrm{mmol} \mathrm{N}^{-1} \mathrm{~d}^{-1} & 0.200 & 0.340 \pm 0.052 \\ 11 & \beta & 1 & 0.750 & 0.925 \pm 0.060 \\ 12 & \gamma_{m} & \mathrm{~d}^{-1} & 0.014 & 0.048 \pm 0.020 \\ 13 & w_{s} & \mathrm{~m} \mathrm{~d}^{-1} & 5.00 & 18.00 \pm 6.93\end{array}$



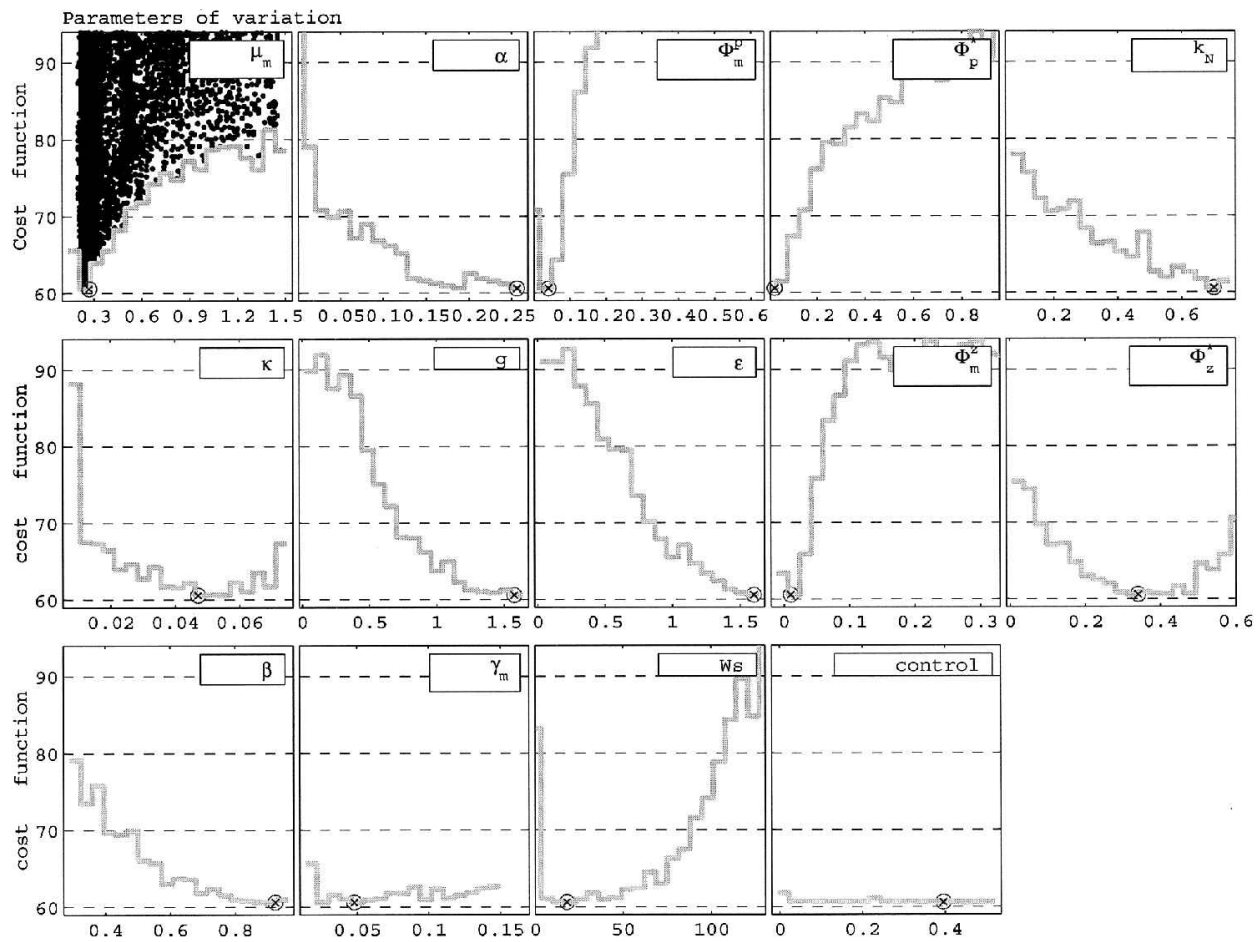

Figure 4. Parameter sets together with their lower limits in costs that occurred during the search process of all four optimizations (the three additional optimizations are included). Every abscissa shows the parameter's value generated during the search process. The corresponding units can be gathered from Table 6. To the first subplot at the top all parameter projections are included (dots). All other subplots simply show the lower limits of these projections. The fourteenth parameter is a control variable and has no effect on the model results.

tion procedure can be used to gain some insight into the cost function's shape. Figure 4 shows parameter guesses during the course of the optimization and their associated costs, projected onto the individual parameter axes. These figures provide information on sensitivities of the cost function to parameter variations and hence on the relative importance of different parameters. Each subplot focuses on a single parameter that varies among the different forward integrations of the model and generates different cost function values (which will depend on values of the other parameters as well). Every combination of parameter values that occurred during the optimization is plotted together with the corresponding cost function value unless the costs exceed $\mathscr{T}_{\text {total }}=95$. The best parameter combination belongs to the lowest cost in the different subplots. Table 6 lists these best parameter estimates together with errors calculated according to Eq. 9. The faster the costs increase with distance from the best parameter value, the larger the cost function's sensitivity with respect to the particular parameter. The subplots cover the full range of 
parameter values between the upper and lower bounds. Under ideal conditions, in a sense that the optimization problem is well posed and the parameters are uncorrelated, all subplots would show sharp symmetric parabolas and the parameters would be fully constrained.

From Figure 4 it can be deduced how well each parameter is constrained. Among those parameters constrained rather well are the phytoplankton growth and loss parameters. Estimates of the phytoplankton growth parameter $\left(\mu_{m}\right)$ smaller than $0.27 \mathrm{~d}^{-1}$ cause a huge increase in costs. The same is true for estimates larger than the optimal value. The cost function sensitivity is less pronounced for the parameter of the photosynthetic efficiency $(\alpha)$. For example, a value of $0.13 \mathrm{~m}^{2} \mathrm{~W}^{-1} \mathrm{~d}^{-1}$ is significantly lower than the best estimate of $0.256 \mathrm{~m}^{2} \mathrm{~W}^{-1} \mathrm{~d}^{-1}$, but it does hardly alter costs. Compared with commonly used values for $\alpha$, the optimization value is larger by an order of magnitude. Possible reasons for this high estimate will be discussed in the next section. The well-constrained parameters describing the mortality of phytoplankton $\left(\Phi_{p}\right.$ and $\left.\Phi_{p}^{*}\right)$ also deviate from values which are conventionally applied: Higher optimal values are found for $\Phi_{p}$, whereas $\Phi_{p}^{*}$ is reduced by a factor of two. A relatively high half-saturation constant is obtained for the nutrient uptake $\left(k_{N}=0.7 \mathrm{mmol} \mathrm{N} \mathrm{m}^{-3}\right)$. The upper limit for $k_{N}$ is not reached but any value lower than $0.7 \mathrm{mmol} \mathrm{N} \mathrm{m}{ }^{-3}$ leads to an increase of the cost function. The relatively high optimal value of $k_{N}$ is somewhat surprising and we had initially expected much lower values because nutrient uptake in the NPZD-model reflects the uptake of both nitrate and ammonium, of which the latter seems to be relevant at low concentrations at the BATS and NABE sites during summer periods. We speculate that the optimal guess of $k_{N}$ is not independent of other parameters. The linkage between a few of the optimal phytoplankton parameter guesses, among which $k_{N}$ is one, will be explained in more detail in the discussion section.

At first glance, the zooplankton parameters appear to be well constrained, but the two grazing parameters ( $g$ and $\epsilon$ ) and the assimilation efficiency $(\beta)$ are actually close to their respective upper bounds imposed to the optimization algorithm. The resulting estimates are close to those applied in other ecosystem models. To effectively constrain zooplankton parameters is difficult with little zooplankton observations and no additional constraints on the grazing rates. In that case the prescribed limits of the parameter range become important. For example, the upper limit avoids the tendency toward an excessive grazing solution which would result in a modeled seasonal maximum of zooplankton biomass that is not resolved by the few available observations (e.g. Fennel et al., 2001; Schartau et al., 2001). In addition, any parameter combination which results in a strong reduction of zooplankton biomass enforces an increase in model-data misfit. Such a particular effect can be identified for $\Phi_{m}^{z}$. But there must also be a maximal tolerable zooplankton biomass, because the quadratic loss parameter for zooplankton $\left(\Phi_{z}^{*}\right)$ reveals an increase of the costs as soon as its value is chosen to be lower than the best estimate. Producing a model solution with unreasonably high zooplankton biomass is likely to draw down the entire phytoplank- 
ton biomass which leads to a data-model mismatch in chlorophyll and primary production after all.

The parameter for the remineralization of detritus $(\gamma)$ is hardly constrained by our cost function. However, the remineralization rate of detritus always depends on the best estimate of the sinking velocity $\left(w_{s}\right)$ and vice versa. The optimal sinking velocity turned out to be significantly higher than proposed for the traditional parameter configuration. Eventually, the remineralization rate increased by a similar factor as the sinking rate. This indicates, that the resulting remineralization profile must be close to that generated by the traditional remineralization parameters.

The final "parameter" is a control which was introduced into the optimization process as well, but which has no effect on the cost function. With this control parameter we are able to determine whether the micro-genetic algorithm has converged to a particular solution for reasons other than being imposed by the shape of the cost function. The last subplot of Figure 4 illustrates that during the search process no preference toward a particular solution occurred. This is indicated by the range of final parameter guesses which still cover the entire search space within the prescribed upper and lower bounds, although a best combination of the other 13 parameters has already been identified.

\section{Discussion}

\section{a. Errors and sensitivity}

Optimal parameter estimates are given by the minimum of the cost function. Nevertheless, the form of the cost function and hence the location of its minimum depends on the actually available observations and their corresponding weights in the cost function. For a better interpretation of the optimal parameter estimates, information on precision, robustness and reliability of the optimization process is desired. To this end, a much simplified Monte Carlo method (with Gaussian noise added to the observations and only 4 realizations) has been applied. Following Eq. (9) this allows us to identify some uncertainties of the optimal parameter estimates which mainly reflect the robustness of the optimization algorithm. With this approach we can test whether we would retrieve a similar solution if our experiment was repeated with slightly different observational values (but of the same data type observed at the same dates).

Note that the additional (synthetic) solutions may be located quite close to the original point in the parameter space but the estimated errors may not recover the full error information which can be deduced from the cost function's sensitivity to parameter variations. For example, the error estimate for the sinking velocity of detritus is close to $7 \mathrm{~m} \mathrm{~d}^{-1}$ for the optimal value of $18 \mathrm{~m} \mathrm{~d}^{-1}$ (Table 6), but Figure 4 reveals that the cost function hardly increases its value even for sinking velocity larger than $25 \mathrm{~m} \mathrm{~d}^{-1}$. On the other hand, the estimated small error of the phytoplankton loss rate parameter $\Phi_{m}^{p}$ is in accordance with the tremendous sensitivity of the cost function (see Fig. 4). As a consequence, the errors given in Table 6 must be jointly interpreted together with cost function sensitivities, as seen in Figure 4. 
The above approach differs from another common error analysis based on the inverse of the Hessian matrix (Fennel et al., 2001; Vallino, 2000). The Hessian is the matrix of the second derivatives of the cost function with respect to the parameters, yielding the curvature or sensitivity. If computed at the minimum of the cost function, it can be used to estimate error bars for the optimal parameter estimates. A great advantage of computing the full Hessian matrix is that off-diagonal elements reveal correlations among the different parameters. In our case the dimension of the parameter space $(=13)$ would be small enough to allow direct computation of the full Hessian at little computational cost. Unfortunately, when the model solution depends nonlinearly on the parameters in the vicinity of the cost function's minimum, the inverse of the Hessian may not be a good approximation to the error covariance (Gunson and Malanotte-Rizzoli, 1996). In addition, the Hessian matrix can only be inverted as long as it remains well conditioned. To have a well-posed optimization problem is hardly the case when data are assimilated into an ecosystem model. In practice, though, this can always be satisfied by adding an a priori constraint on the first parameter estimates to the cost function. However, we deliberately avoided such $a$ priori assumptions on the parameter values.

\section{b. Parameter estimates}

The identification of phytoplankton growth parameters is of great importance for algorithms which derive primary production rates from satellite data (Platt and Sathyendranath, 1999; Platt and Longhurst, 2000). The maximum growth rate of phytoplankton in the NPZD-model depends on the ambient temperature and on the optimal estimate of the growth rate parameter $\left(\mu_{m}\right)$. Accounting for the typical temperatures at the three different sites, the resulting maximum growth rates within the uppermost layer are about $1.8 \mathrm{~d}^{-1}$ at the BATS location, $1.1 \mathrm{~d}^{-1}$ at the NABE site, and $0.8 \mathrm{~d}^{-1}$ at OWS-INDIA. The seasonal cycles of the modeled depth averaged maximum growth rates at the respective sites are shown in Figure 5. Evans (1999) used the same growth function but optimized a temperature independent maximum growth rate directly and obtained an estimate of $0.95 \mathrm{~d}^{-1}$ when assimilating only NABE-data into a FDM-model. This is in good agreement with our averaged rate for the NABE site. For the same location, the estimates of Fasham and Evans (2000) were higher, ranging from $2.02 \mathrm{~d}^{-1}$ for the FDM-model to $1.27 \mathrm{~d}^{-1}$ for a modified version with an additional diatom compartment. Nevertheless, the above comparison reveals that our growth rate estimate of $0.27 \mathrm{~d}^{-1}$ (times the temperature factor) is at the low end of estimates derived from data assimilation studies. Reasons for this low estimate of $\mu_{m}$ must be discussed within a broader context, including other phytoplankton growth parameters as well, namely the initial slope parameter $\alpha$ (photosynthetic efficiency) and the half saturation constant for nitrogen uptake $\left(k_{N}\right)$. For a similar ecosystem model, Fennel et al. (2001) demonstrated that the maximum growth rate can be negatively correlated with the initial-slope parameter $(\alpha)$ parameter and the half-saturation constant for nitrogen uptake $\left(k_{N}\right)$. This is consistent with our results, where low growth rates coincide with high estimates of $\alpha$ and $k_{N}$. Our results of $\alpha$ are close to 


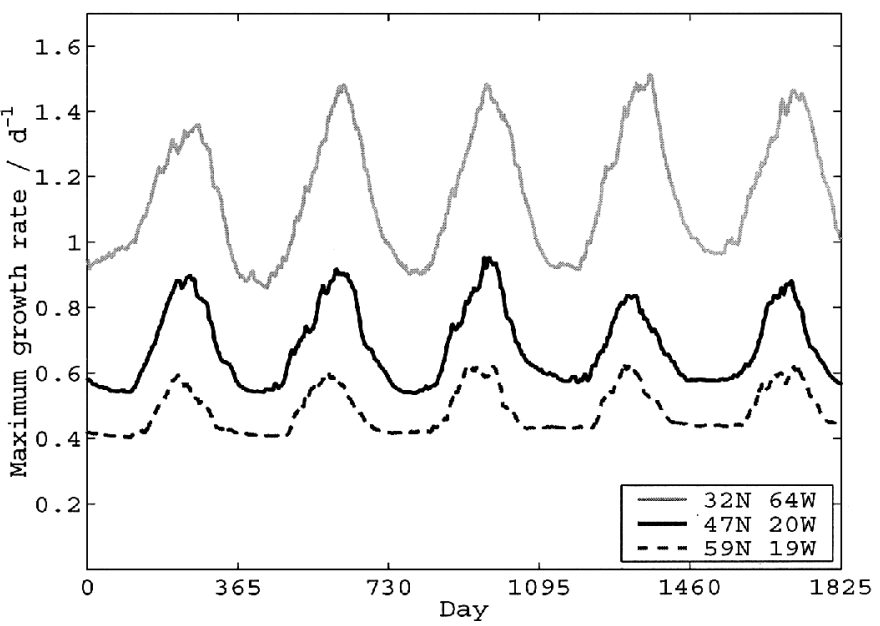

Figure 5. Modeled phytoplankton maximum growth rates averaged over the upper 35 meters. Seasonal cycle at the BATS site (gray line), the location of NABE (black line), and at OWS-INDIA (dashed line).

$0.25 \mathrm{~m}^{2} \mathrm{~W}^{-1} \mathrm{~d}^{-1}$, which is a factor of ten larger than the preferentially used value. Estimates for $\alpha$ close to the traditional value were obtained by Fennel et al. (2001) for BATS data $\left(\alpha=0.0245 \mathrm{~m}^{2} \mathrm{~W}^{-1} \mathrm{~d}^{-1}\right)$ and by Evans (1999) at the NABE site $\left(0.035 \mathrm{~m}^{2} \mathrm{~W}^{-1} \mathrm{~d}^{-1}\right)$. However, these two studies both comprised a priori parameter information in their cost functions which was $\alpha=0.025 \mathrm{~m}^{2} \mathrm{~W}^{-1} \mathrm{~d}^{-1}$. Other dataassimilation experiments found a tendency toward higher values of $\alpha$ as well (e.g. 0.164 and $0.222 \mathrm{~m}^{2} \mathrm{~W}^{-1} \mathrm{~d}^{-1}$ in Fasham and Evans (2000) or $0.93 \mathrm{~m}^{2} \mathrm{~W}^{-1} \mathrm{~d}^{-1}$ in Hurtt and Armstrong (1999)). Similar values were estimated for a NPZ-model at the BATS location, ranging from $\alpha=0.173$ to $0.688 \mathrm{~m}^{2} \mathrm{~W}^{-1} \mathrm{~d}^{-1}$ (Schartau et al., 2001). The extremely high estimate of Hurtt and Armstrong (1999) was attributed to the circumstance that the initial time of the bloom at OWS-INDIA had to be fitted by their model correctly, getting a rapid bloom under low light conditions. Such a scenario is consistent with a time lag in simulated stratification at the OWS-INDIA location (see accompanying paper Schartau and Oschlies, 2003).

To investigate which of the three locations enforced the high estimates of $\alpha$, Figure 6 resolves changes in the cost function that arise from varying two parameters, $\mu_{m}$ and $\alpha$, respectively. Subplot $6 \mathrm{~A}$ shows the shape of the cost function with the minimum at the optimal combination of $\mu_{m}$ and $\alpha$. The other subplots (6B-D) split up the cost function into the contributions that come from each location. The high estimates of $\alpha$ together with low growth rates result from the misfit contributions at the BATS and OWS-INDIA sites. Furthermore, plot $6 \mathrm{C}$ reveals that a locally optimal parameter combination differs from the overall optimal solution (global minimum). This is of particular interest since it also proves that a single optimization at the NABE site would result in a different parameter set, e.g. 

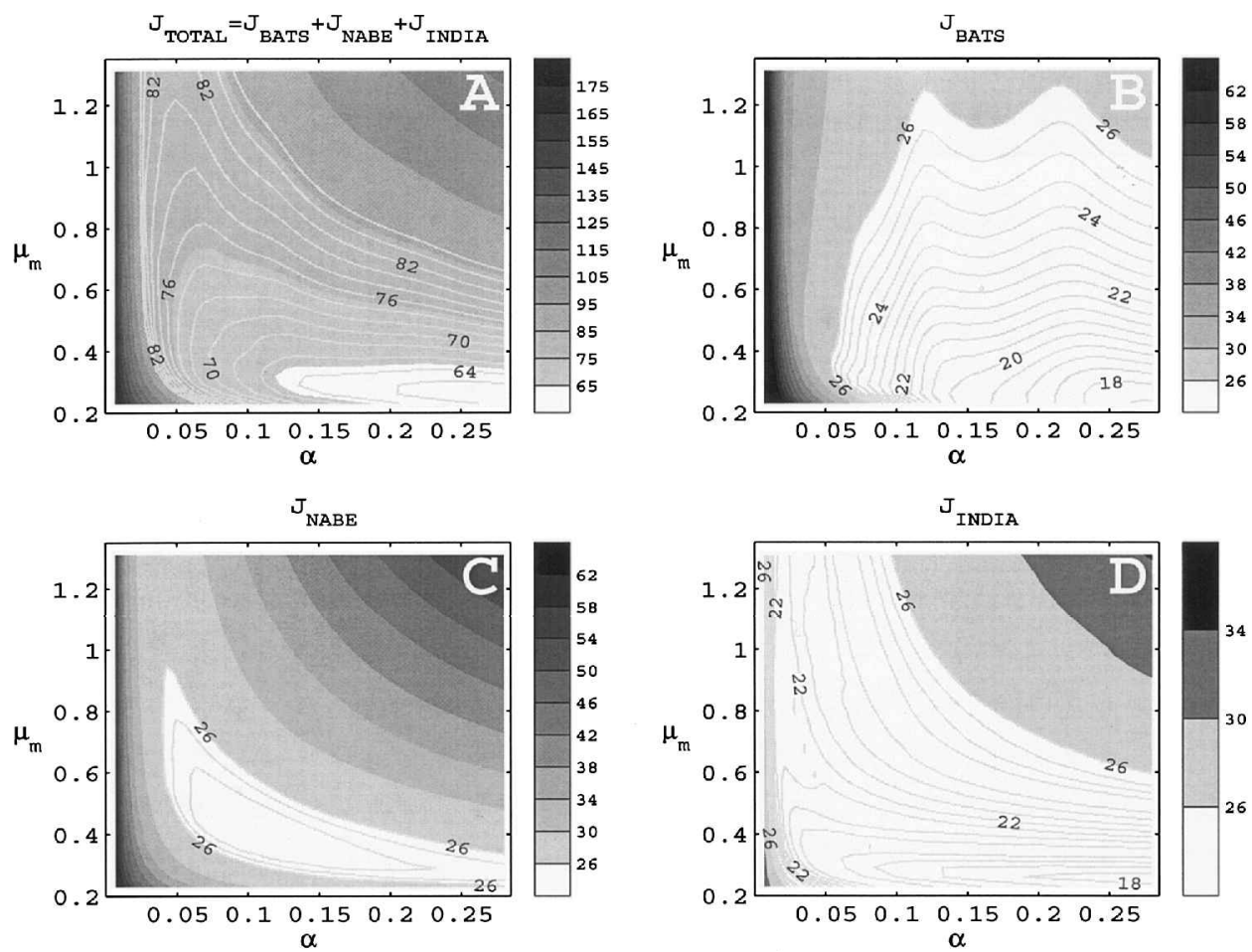

Figure 6. Two-dimensional variations of the initial slope parameter $(\alpha)$ and the growth rate parameter $\left(\mu_{m}\right)$. Plot A shows the contours of the overall costs (as seen by the optimization algorithm). Subplots B-D reveal the individual contributionsto the cost function at every location.

estimates of $\mu_{m}$ and $\alpha$ close to $0.4 \mathrm{~d}^{-1}$ and $0.12 \mathrm{~m}^{2} \mathrm{~W}^{-1} \mathrm{~d}^{-1}$, respectively. If $\alpha$ is set to a traditional value, the cost function increases mainly due to the misfit contributions in DIN and Chl $a$ (Fig. 7). The increase in costs is dominated by changes in Chl $a$ at the BATS site during all months, suggesting that $\alpha$ is constrained mainly by chlorophyll observations. Naturally, it is the beginning of a phytoplanktonbloom which is sensitive to variations in $\alpha$ and the model is brought into better agreement with observations when the high estimate of $\alpha$ is applied. Low parameter values induce a significant phase shift in the initialization of the phytoplankton bloom which generate large misfits between model result and observations (not shown). Apparently, the stratification scenario at OWS-INDIA is not solely responsible for the optimal estimates, as discussed by Hurtt and Armstrong (1999). It is rather a general model deficiency at the initial bloom phase. Here, a good example is found for a parameter estimate which will compensate for a model deficiency. Apart from the initialization of the phytoplankton blooms, high estimates of $\alpha$ also affect the estimation of the other growth parameters such as $k_{N}$ and $\mu_{m}$. Since $\alpha$ remains constant throughout the season, its high value causes light saturated growth conditions to great depths during the 
Cost function contributions of DIN

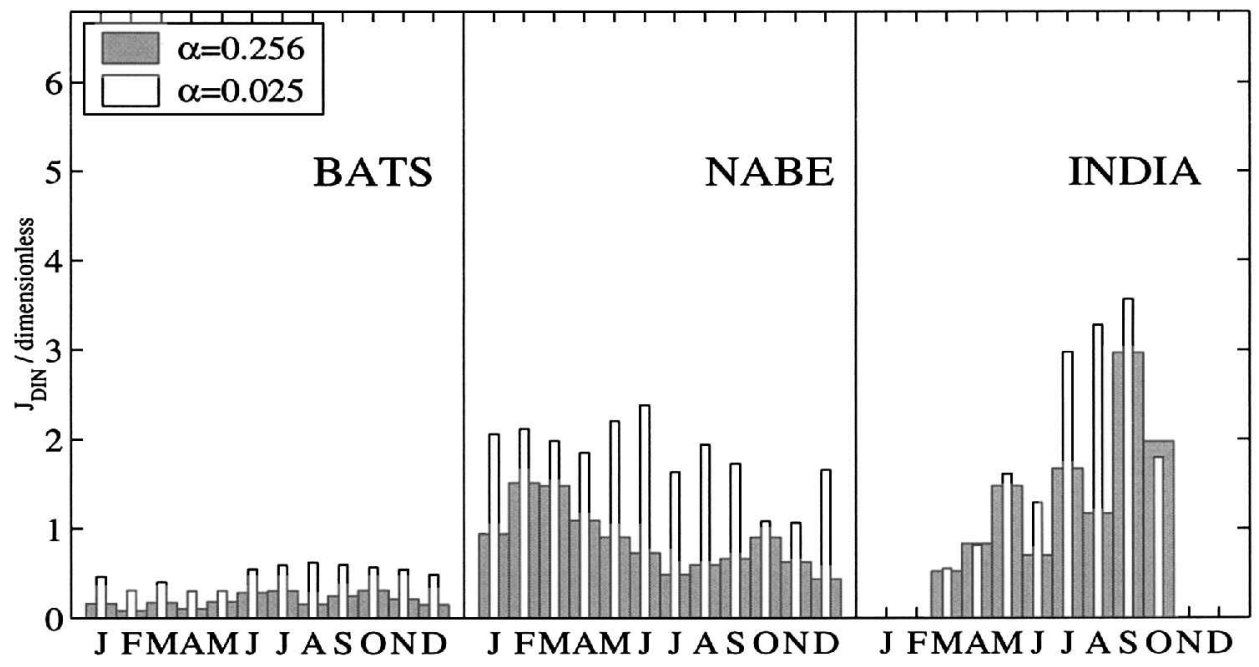

Cost function contributions of CHL a

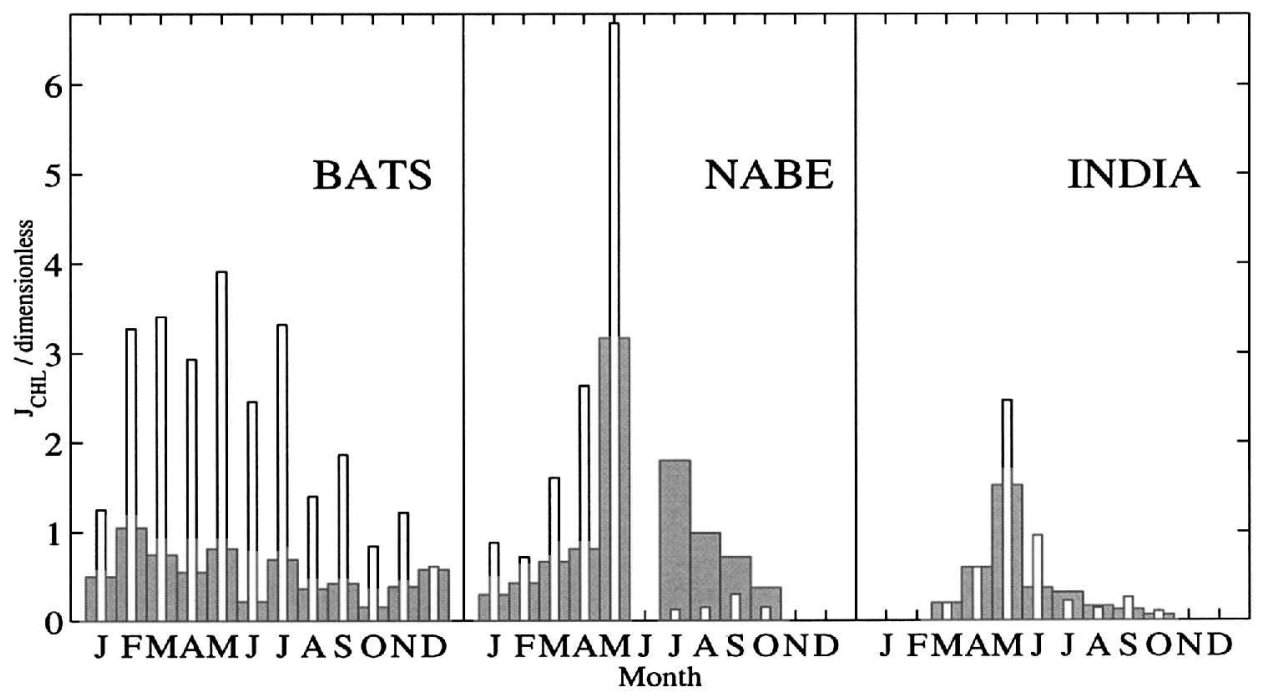

Figure 7. Cost function contributions of DIN and Chl $a$ at all three locations of interest. The misfit contributions are added up for each month at the respective site. Gray bars show the remaining misfits after optimization. White bars indicate the misfits which result when the initial slope parameter $(\alpha)$ is set to its traditionally proposed value of $0.025 \mathrm{~m}^{2} \mathrm{~W}^{-1} \mathrm{~d}^{-1}$. 
summer periods as well. But at depth between 50 to 100 meters, the modeled primary production rates are already higher than observed, as discussed in an accompanying paper Schartau and Oschlies (2003; this issue). The depth of the deep chlorophyll maximum during summer depends on estimates of $\alpha$, whereas the magnitude of the modeled deep chlorophyll concentration is largely controlled by the other growth rate parameters, $k_{N}$ and $\mu_{m}$, respectively. Hence, low growth rates are preferentially generated during the search process in order to minimize this individual misfit contribution.

High optimal estimates of $\alpha$ resulted for models that compute a daily average of the light limited growth (Evans and Parslow, 1985) and do not account for diurnal variations in mixing. More precisely, such a daily average of the light-limited growth rate remains constant when integrating the phytoplankton equations throughout a single day (here 23 time steps for integration). Note that the net light availability for phytoplankton within the mixed layer can be enhanced when short-termed diurnal stratification occurs while daylight becomes maximal. Such day and night changes in mixing depth can be significant (Woods and Onken, 1982; Woods and Barkmann, 1986). When diurnal mixed-layer variations are neglected, the net light availability of cells trapped in the mixed layer at noon will be underestimated. We speculate that these effects are also present in our model, but are to some extent compensated by the parameter optimization. In order to receive improved estimates of $\alpha$, we suggest a better accounting of the dynamics and physicalbiological interactions during the initial bloom periods. Resolving diurnal mixing and a diurnal cycle for radiation is likely to make up for part of the models deficiency. Furthermore, if this model error is corrected, it would have a positive effect on other parameter estimates as well, such as on $\mu_{m}$ and $k_{N}$.

The dynamics of the photosynthetic efficiency itself may also be improved. For example, in Geider et al. (1998) $\alpha$ is modeled as a chlorophyll specific parameter, depending on the chlorophyll to carbon ratio. Furthermore, the authors suggest that the dynamical behavior of photosynthesis can be improved in the model when treating $\alpha$ as the product of a light-absorption efficiency and a maximum light-limited quantum efficiency. The light-absorption efficiency could then be treated as a function of the chlorophyll to nitrogen ratio while the quantum efficiency becomes a function of DIN availability (it decreases under nitrate depleted conditions). Hence, low light and nutrient replete conditions would yield a high value for $\alpha$ whereas high light and low DIN concentrations would result in low values. Another sophisticated parameterization for the photosynthetic efficiency has been suggested by Bissett et al. (1999), who have explicitly linked the pigment content with light absorption and actual energy utilization. Apart from the diurnal mixing effect, such improved dynamics is likely to account for a major fraction of our present model error.

While difficulties in finding reliable estimates of the phytoplankton growth parameters can be attributed to model deficiencies, the problems in estimating remineralization and export parameters are rather due to the constraints entering the cost function. In particular, the observational data are insufficient to constrain the modeled phytoplankton sinks. 
Phytoplankton losses can occur either via export of particle aggregates or by zooplankton grazing. Our estimates of the grazing parameters are close to the imposed upper bounds. With these constraints we prevented the model to invoke a solution where high phytoplankton production rates and low chlorophyll concentrations are possible because of excessive grazing. However, the zooplankton parameters yield grazing rates between 1.5 and $1.6 \mathrm{~d}^{-1}$ which may be too high because other processes responsible for a phytoplankton drawdown, such as cell coagulation and sinking of aggregates, are not sufficiently accounted for in the model. If more zooplankton data were available, the choice of the upper bounds may become irrelevant and the modeled zooplankton biomass could be better optimized toward observations. With respect to the export, the two parameters of the detritus compartment are of special interest: the remineralization rate and the sinking velocity. The problem here is that both parameters cannot be estimated independently. Similar amounts of nutrients can be remineralized when sinking velocity and remineralization rate increase in the same proportions. Therefore, the estimated sinking velocity of $18 \mathrm{~m} \mathrm{~d}^{-1}$ needs to be considered in combination with the remineralization rate of $0.048 \mathrm{~d}^{-1}$. It is noteworthy that the optimal estimates of the remineralization rate found here are constrained better than in an ecosystem model of the upper mixed layer only (Schartau et al., 2001). Doney et al. (1996) proposed sinking rates of $10 \mathrm{~m} \mathrm{~d}^{-1}$ together with a remineralization rate of $0.1 \mathrm{~d}^{-1}$, matching a depth scale of remineralization of $100 \mathrm{~m}$ estimated from shallow sediment trap data by Lohrenz et al. (1992) for the BATS site. For the optimal parameters obtained here, the depth scale of remineralization becomes $375 \mathrm{~m}$. The recycling of organic material of zooplankton is expressed as a linear temperature-dependent loss term in our model. When referring to the average temperature range at the three distinct locations, the flux rates of nitrogen, from the zooplankton compartment back to its dissolved inorganic form, remain close to the traditionally temperature-independent constant rate. The best estimate for the linear remineralization rate of organic, presumably labile, nitrogen from phytoplankton to DIN is three times larger those values used in previous model studies at the respective sites. Similar results were obtained by the data-assimilation study of Spitz et al. (2001). The authors pointed out the important role of bacteria for effectively utilizing dissolved organic nitrogen. Although this process is crudely resolved in the NPZD-model, our optimization result point toward high remineralization rates of labile organic material.

\section{Summary and conclusion}

A relatively simple $N P Z D$ ecosystem model has been fitted to observations at three locations in the North Atlantic which reflect very different ecosystems. The minimum model-data misfit as measured by the minimum cost function value is about three times higher than could be reached by a model that was, apart from observational errors, fully consistent with the data. The reliability and robustness of the optimization procedure based on a genetic algorithm $(\mu \mathrm{GA})$ is approved by additional optimizations with resampled data with added noise and by starting from different initial parameter guesses. For our 
discussion of parameter values, we have found that the optimal combination of parameters, e.g. $\mu_{m}$ and $\alpha$, at the NABE site can differ from values being optimal for the other locations. This is not a great surprise, but it clarified how the parameter estimates need to be interpreted. For example, if a different scaling approach was chosen and different weights were assigned, the misfits at the NABE location could have altered the overall optimal estimates toward lower values for $\alpha$ and higher estimates for the growth rate. Hence, the optimal parameter results are a compromise among all three locations, and the estimates are sensitive to the chosen scaling approach (which gives weights to the different locations). Nevertheless, one has to accept that ecosystem models always remain simplified representations of the real biogenic environment. It will, therefore, hardly be possible to give reliable approximations of biogeochemical fluxes without carefully investigating the model's parameter space as well. Such an exercise reflects the limits and weaknesses of the model assumptions. This study shows that data-assimilation experiments in ecosystem modeling are useful and can promote new model approaches. From our parameter optimization study we came up with the following conclusions:

a. The optimization resulted in unexpectedly high estimates of $\alpha$. In fact, the optimized value of $\alpha$ is at the upper bound of the searchable parameter range. The model requires high values of $\alpha$ in order to reproduce observed chlorophyll concentrations mainly at the BATS site and, although less accentuated, at the location of OWS-INDIA. It is concluded that a high estimate $\alpha$ compensates for a model deficiency. We suspect that the assumptions entering time-integrated functions for light limited growth might be inadequate.

b. High optimal values for the temperature-dependent phytoplankton loss rates are obtained. These high estimates are crucial for enhancing primary production rates by a rapid transformation of organic material back to its inorganic forms which are subsequently available for phytoplankton growth.

c. The optimal parameter estimates must be interpreted as a compromise, albeit a reasonable one, among the three locations. This compromise will be sensitive to the chosen scaling approach, giving different weights to the individual locations. Hence, important parameters, such as those entering phytoplankton growth rate parameterizations, should be more dynamical in order to better account for the different ecosystem conditions found at the three different locations.

Acknowledgments. First of all, we thank everyone who supplied us with profile measurements. Many very helpful and constructive suggestions were made by the referees and we greatly acknowledge their efforts. We thank the staff of BBSR for making their very valuable data available through the US-JGOFS web-pages. We were generously supported by Roy Lowry and Polly Hadziabdic at the BODC. We thank Wolfgang Koeve, Joachim Hermann, and Mike Fasham who supported us with complementary data for $47 \mathrm{~N} 20 \mathrm{~W}$ and $59 \mathrm{~N} 19 \mathrm{~W}$. The work presented in this paper was partly supported by the Deutsche Forschungsgemeinschaft (DFG). 


\section{APPENDIX}

\section{NPZD-equations}

Dissolved inorganic nitrogen

$$
\operatorname{sms}(N)=\left[-J(\mu, u)+\Phi_{p}(T)\right] P+\Phi_{z}(T) Z+\gamma(T) D
$$

Phytoplankton biomass

$$
\operatorname{sms}(P)=\left[J(\mu, u)-\Phi_{p}(T)-\Phi_{p}^{*} P\right] P-G \cdot Z
$$

Herbivorous zooplankton

$$
\operatorname{sms}(Z)=\left[\beta G-\Phi_{z}(T)-\Phi_{z}^{*} Z\right] Z
$$

Detritus

$$
\operatorname{sms}(D)=\left[(1-\beta) G-\Phi_{z}^{*} Z\right] Z+\Phi_{p}^{*} P^{2}-\gamma(T) D-w_{s} \frac{\partial D}{\partial z}
$$

with the nutrient uptake rate $u=N /\left(k_{N}+N\right)$.

A Holling type III function is utilized for simulating the grazing:

$$
G(\epsilon, g)=\frac{g \epsilon P^{2}}{g+\epsilon P^{2}}
$$

The growth function $J(z, \mu, u)$ uses the minimum principle of von Liebig (1840):

$$
J(\mu, u)=\min \left(\bar{\mu}(z), V_{p} \cdot u\right)
$$

with the analytical solution for the depth integrated light-limited growth $\bar{\mu}(z)$ according to Evans and Parslow (1985), integrating over the vertical grid box at depth $z$ (Oschlies and Garçon, 1999).

The maximal phytoplankton growth rate and the remineralization parameters are temperature $\left(T\left[{ }^{\circ} \mathrm{C}\right]\right)$ dependent:

$$
\begin{array}{rr}
V_{p}=\mu_{m} \cdot \text { func }_{T}, & \gamma(T)=\gamma_{m} \cdot \text { func }_{T} \\
\Phi_{z}(T) & =\Phi_{m}^{z} \cdot \text { func }_{T}, \quad \Phi_{p}(T)=\Phi_{m}^{p} \cdot \text { func }_{T}
\end{array}
$$

with

$$
\text { func }_{T}=\left(C_{r e f}\right)^{c T}
$$

as used in Sarmiento et al. (1993) and Fasham et al. (1993).

The daily, depth-averaged chlorophyll to carbon ratio $\left(\Theta_{C}^{C h l}\right)$ in the dimensions [mg Chl $\mathrm{mg} \mathrm{C}^{-1}$ ] is calculated according Cloern et al. (1995): 
$\Theta_{C}^{C h l}=0.003+0.0154 \cdot(\exp (0.050 \cdot T))$

$$
\times\left[\exp \left(\frac{-0.059 \cdot \operatorname{PAR}(1-\exp (-\Lambda z))}{\Lambda z}\right)\right] \cdot u
$$

with the total attenuation coefficient $\Lambda=k_{w}+\kappa \cdot P$. In Eq. (18) PAR is in the units [mol quanta $\mathrm{m}^{-2} \mathrm{~d}^{-1}$ ], (for PAR $1.0 \mathrm{~W} \mathrm{~m}^{-2} \approx 0.4$ mol quanta $\mathrm{m}^{-2} \mathrm{~d}^{-1}$ ). For a given constant molar C:N Redfield ratio of $106: 16$ then $1 \mathrm{mg} \mathrm{C}$ is equivalent to 12.58 . $10^{-3} \mathrm{mmol} \mathrm{N}$ and the chlorophyll to nitrogen ratio for the model counterpart in the dimensions [mg Chl $a$ mmol N${ }^{-1}$ ] becomes 79.5 $\cdot \Theta_{C}^{C h l}$.

\section{REFERENCES}

Athias, V., P. Mazzega and C. Jeandel. 2000. Selecting a global optimization method to estimate the oceanic particle cycling rate constants. J. Mar. Res., 58, 675-707.

Bissett, W., J. Walsh, D. Dieterle and K. Carder. 1999. Carbon cycling in the upper waters of the Sargasso Sea: I. Numerical simulations of different carbon and nitrogen fluxes. Deep-Sea Res. I, 46, 205-269.

Caron, D. A., H. G. Dam, P. Kremer, E. J. Lessard, L. P. Madin, T. C. Malone, J. M. Napp, E. R. Peele, M. R. Roman and M. J. Youngbluth. 1995. The contribution of microorganisms to particulate carbon and nitrogen in surface waters of the Sargasso Sea near Bermuda. Deep-Sea Res. I, 42, 943-972.

Carroll, D. L. 1996. Chemical laser modeling with genetic algorithms. Amer. Inst. Aero. Astro., 34, $338-346$.

Cloern, J. E., C. Grenz and L. Vidergar-Lucas. 1995. An empirical model of the phytoplankton chlorophyll:carbon ratio- the conversion factor between productivity and growth rate. Limnol. Oceanogr., 40, 1313-1321.

Conkright, M. E., S. Levitus and T. B. Boyer. 1994. World Ocean Atlas 1994, Vol. 1: Nutrients. National Oceanic and Atmospheric Administration Atlas NESDIS 1, U.S. Gov. Print. Office, Washington, D.C, $162 \mathrm{pp}$.

Doney, S. C., D. Glover and R. Najjar. 1996. A new coupled, one-dimensional biological-physical model for the upper ocean: Applications to the JGOFS Bermuda Atlantic Time-Series Study (BATS) site. Deep-Sea Res. II, 43, 625-651.

Ducklow, H. W. and R. P. Harris. 1993. Introduction to the JGOFS North Atlantic bloom experiment. Deep-Sea Res. II, 40, 1-8.

Efron, B. 1994. The Bootstrap, in The Jackknife, the Bootstrap, and Other Resampling Plans (sixth printing), B. Efron, ed., Capital City Press, Montpelier, VT, 91 pp.

Eppley, R. W. 1972. Temperature and phytoplankton growth in the sea. Fishery Bull., 17, 15-24.

Evans, G. T. 1999. The role of local models and data sets in the Joint Global Ocean Flux Study. Deep-Sea Res. I, 46, 1369-1389.

Evans, G. T. and J. S. Parslow. 1985. A model of annual plankton cycles. Biol. Oceanogr., 3, $328-347$.

Fasham, M. J. R., H. W. Ducklow and S. M. McKelvie. 1990. A nitrogen-based model of plankton dynamics in the oceanic mixed layer. J. Mar. Res., 48, 591-639.

Fasham, M. J. R. and G. T. Evans. 1995. The use of optimization techniques to model marine ecosystem dynamics at the JGOFS station at 47N 20W. Phil. Trans. Roy. Soc. London, B348, 203-209.

2000. Advances in ecosystem modelling within JGOFS, in The Changing Ocean Carbon Cycle, R. B. Hanson, H. W. Ducklow, and J. G. Field, eds., Cambridge University Press. 417-446. 
Fasham, M. J. R., J. L. Sarmiento, R. D. Slater, H. W. Ducklow and R. Williams. 1993. Ecosystem behaviour at Bermuda station "s" and Ocean weather station "India": A general circulation model and observational analysis. Global Biogeochem. Cycles, 7, 379-415.

Fennel, K., M. Losch, J. Schroeter and M. Wenzel. 2001. Testing a marine ecosystem model: Sensitivity analysis and parameter optimization. J. Mar. Syst., 28, 45-63.

Geider, R. J., H. L. MacIntyre and T. M. Kana. 1998. A dynamic regulatory model of phytoplankton acclimation to light, nutrients, and temperature. Limnol. Oceanogr., 43, 679-694.

Goldberg, D. E. 1989. Genetic Algorithms in Search, Optimization and Machine Learning, AddisonWesley, Reading, MA, 432 pp.

Gunson, J. R. and P. M. Malanotte-Rizzoli. 1996. Assimilation studies of open-ocean flows: 2. Error measures with strongly nonlinear dynamics. J. Geophys. Res., 101(C12), 28473-28488.

Holland, J. H. 1975. Adaptation in Natural and Artificial Systems, A Bradfford Book, Univ. Michigan Press.

Hurtt, G. C. and R. Armstrong. 1996. A pelagic ecosystem model calibrated with BATS data. Deep-Sea Res. II, 43, 653-683.

-1999. A pelagic ecosystem model calibrated with BATS and OWSI data. Deep-Sea Res. I, 46, 27-61.

Krishnakumar, K. 1989. Micro-genetic algorithms for stationary and non-stationary function optimization. Intel. Control and Adaptive Syst., 1196, 289-296.

Lohrenz, S. E., G. A. Knauer, V. L. Asper, M. Tuel, A. F. Michaels and A. H. Knap. 1992. Seasonal and interannual variability in primary production and particle flux in the northwestern Sargasso Sea: U.S. JGOFS Bermuda Atlantic time-series study. Deep-Sea Res. I, 39, 1373-1391.

Matear, R. J. 1995. Parameter optimization and analysis of ecosystem models using simulated annealing. J. Mar. Res., 53, 571-607.

Michaels, A. and A. Knap. 1996. Seasonal patterns of ocean biogeochemistry at the U.S. JGOFS Bermuda time-series study site. Deep-Sea Res. II, 43, 157-198.

Moore, K. J., S. C. Doney, J. A. Kleypas, M. David and I. Y. Fung. 2001. An intermediate complexity marine ecosystem model for the global domain. Deep-Sea Res. II, 49, 403-462.

Oschlies, A. 2001. NAO-induced long-term changes in nutrient supply to the surface waters of the North Atlantic. Geophys. Res. Lett., 28, 1751-1754.

Oschlies, A. and V. Garçon. 1999. An eddy-permitting coupled physical-biologica model of the North Atlantic. 1. Sensitivity to advection numerics and mixed layer physics. Global Biogeochem. Cycles, 13, 135-160.

Oschlies, A., W. Koeve and V. Garçon. 2000. An eddy-permitting coupled physical-biological model of the North Atlantic. 2. Ecosystem dynamics and comparison with satellite and JGOFS local studies data. Global Biogeochem. Cycles, 14, 499-523.

Platt, T. S. S. and A. Longhurst. 2000. Remote sensing of primary production in the ocean: Promise and fulfilment, in The Changing Ocean Carbon Cycle, R. B. Hanson, H. W. Ducklow, and J. G. Field, eds., Cambridge University Press, 447-465.

Platt, T. and S. Sathyendranath. 1999. Spatial structure of pelagic ecosystem processes in the global ocean. Ecosystems, 2, 384-394.

Sarmiento, J. L., R. D. Slater, M. J. R. Fasham, H. W. Ducklow, J. R. Toggweiler and G. T. Evans. 1993. A seasonal three-dimensional ecosystem model of nitrogen cycling in the North Atlantic euphotic zone. Global Biogeochem. Cycles, 7, 417-450.

Schartau, M. 2001. Data-assimilation studies of marine, nitrogen-based, ecosystem models in the North Atlantic Ocean. Ph.D. thesis, Naturwissenschaftliche Fakultät der Christian-AlbrechtsUniversität zu Kiel, 127 pp.

Schartau, M. and A. Oschlies. 2003. Simultaneous data-based optimization of a 1D-ecosystem model 
at three locations in the North Atlantic Ocean: Part II-Standing stocks and nitrogen fluxes. J. Mar. Res., 61, 795-821.

Schartau, M., A. Oschlies and J. Willebrand. 2001. Parameter estimates of a zero-dimensional ecosystem model applying the adjoint method. Deep-Sea Res. II, 48, 1769-1800.

Spitz, Y. H., J. R. Moisan and M. R. Abbott. 2001. Configuring an ecosystem model using data from the Bermuda Atlantic time series (BATS). Deep-Sea Res. II, 48, 1733-1768.

Spitz, Y. H., J. R. Moisan, M. R. Abbott and J. G. Richman. 1998. Data assimilation and a pelagic ecosystem model: parameterization using time series observations. J. Mar. Syst., 16, 51-68.

Steele, J. H. and E. W. Henderson. 1992. The role of predation in plankton models. J. Plank. Res., 14, $157-172$.

Vallino, J. J. 2000. Improving marine ecosystem models: Use of data assimilation and mesocosm experiments. J. Mar. Res., 58, 117-164.

Verity, P. G., D. K. Stoecker, M. E. Sieracki and J. R. Nelson. 1993. Grazing, growth and mortality of microzooplanktonduring the 1989 North Atlantic spring bloom at 47N 18W. Deep-Sea Res. I, 40, 1793-1814.

von Liebig, J. 1840. Organic Chemistry in its Applications to Agriculture and Physiology. Taylor and Walton, London.

Williams, R. 1988. Spatial heterogeneity and niche differentiationin oceanic zooplankton. Hydrobiologia, 167/168, 151-159.

Woods, J. D. and W. Barkmann. 1986. The response of the upper ocean to solar heating. I: The upper mixed layer. Quart. J. Roy. Meteor. Soc., 112, 1-27.

Woods, J. D. and R. Onken. 1982. Diurnal variation and primary production in the ocean-preliminary results of a lagrangian ensemble model. J. Plank. Res., 4, 735-756.

Received: 19 August, 2002; revised: 23 December, 2003. 